\title{
JOURNAL.RU
}

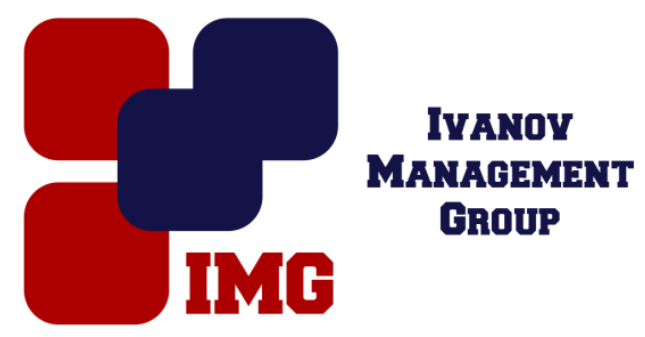

Баклаева Н.M.

Филиал ФГБОУ ВО «Российский экономический университет имени Г.В. Плеханова» 6 г. Пятигорске Ставропольского края Пятигорск, Россия

doi: $10.18411 / 1 \mathrm{j}-31-07-2017-47$

idsp 000001:1j-31-07-2017-47

\section{Новые технологии реализации межбюджетных отношений}

\section{Аннотация}

В современных условиях обостряются противоречия в системе межбюджетных отношений. Так, в 2014-2016 годах при сохранении дефицита федерального бюджета, применение ранее использовавшегося маневра поддержания уровня расходов местных и региональных бюджетов посредством трансфертов из федерального бюджета оказалось невозможным и в результате можно наблюдать одновременное сокращение как межбюджетных трансфертов, так и объемов расходов консолидированных бюджетов субъектов РФ. Для преодоления сложившегося положения предлагается формирование и введение в повседневную практику финансового инструментария реализации межбюджетных отношений на основе технологии блокчейн.

Ключевые слова: федеральный бюджет, консолидированные бюджеты, система межбюджетных отношений, межбюджетные трансферты, технологии блокчейн

В настоящее время в российской экономике наблюдается достаточно высокая зависимость субфедерального уровня бюджетной системы от межбюджетных трансфертов $[1,3,4,12]$. Так, совокупный объем безвозмездных поступлений в консолидированные бюджеты субъектов Федерации в период с 2005 по 2016 годы увеличился с 442,3 до 1634,5 млрд. руб., что в реальном выражении составило прирост в $29,6 \%$. 
Данные изменения достаточно хорошо иллюстрируют принципы функционирования отечественной системы межбюджетных отношений [6, 7, 10]. Так, в 2009 году, когда многие территории страны столкнулись с проблемой неисполнения доходов местных и региональных бюджетов вследствие резко ухудшившейся на рубеже 2008-2009 годов экономической ситуации, посредством трансфертов из федерального бюджета нижестоящим бюджетам и бюджетам государственных и территориальных внебюджетных фондов удалось избежать резкого сокращения расходов данных социально значимых уровней бюджетной системы. В результате этого можно было наблюдать практически отсутствовавшее сокращение расходов консолидированных бюджетов субъектов РФ в этот период. Однако вместе с тем произошло резкое увеличение расходов федерального бюджета, приведшее к его дефициту и увеличению государственного долга. При повторении подобной ситуации в 2014-2016 годах и сохранении дефицита федерального бюджета, применение подобного маневра стало невозможным. В результате можно наблюдать одновременное сокращение как межбюджетных трансфертов, так и расходов консолидированных бюджетов субъектов РФ.

Следствием данной системной особенности является высокая зависимость доходов и, соответственно, расходов субфедерального уровня бюджетной системы от федеральных межбюджетных трансфертов. Для подтверждения или опровержения высказанного предположения можно произвести расчет ковариации и коэффициента корреляции - показателей, характеризующих наличие и силу связи между значениями двух переменных величин. При этом следует учитывать, что и исходный показатель суммы межбюджетных поступлений, и исходный показатель доходов консолидированных бюджетов субъектов РФ представляют собой ряды динамики, обладающие определенными тенденциями, а расчет ковариации и корреляции по рядам динамики, обладающим тенденцией, может привести к установлению ложной корреляции. Для предотвращения данного варианта, необходимо исходные ряды динамики очистить от присущих им тенденций. В таком случае, о связи двух рядов динамики можно судить исходя из взаимного изменения случайных компонент данных рядов динамики. В качестве таковых компонент можно использовать цепные темпы прироста значений каждого из рядов динамики. Поэтому для оценки ковариации и корреляции между значениями показателей межбюджетных поступлений и доходов консолидированных бюджетов субъектов РФ рассчитаем цепные темпы прироста. В табл. 1 представлены 
значения темпов прироста межбюджетных поступлений и доходов консолидированных бюджетов субъектов РФ. Ценовые данные скорректированы на уровень инфляции и выражены в постоянных ценах базисного периода.

Таблица 1.

Расчет показателей изменения суммы межбюджетных поступлений и доходов консолидированных бюджетов субъектов $Р \Phi^{*}$

\begin{tabular}{|c|c|c|c|c|c|c|c|c|c|c|c|c|}
\hline Показатели & 2005 & 2006 & 2007 & 2008 & 2009 & 2010 & 2011 & 2012 & 2013 & 2014 & 2015 & 2016 \\
\hline $\begin{array}{c}\text { Межбюджетные } \\
\text { поступления в } \\
\text { консолидированные } \\
\text { бюджеты субъектов } \\
\text { РФ в основных } \\
\text { рыночных ценах, } \\
\text { млрд. руб. }\end{array}$ & 424,5 & 581,8 & 627,3 & 1132,6 & 1487,5 & 1398,9 & 1644,5 & 1624,4 & 1515,0 & 1670,8 & 1616,7 & 1578,1 \\
\hline \begin{tabular}{|c|} 
Доходы \\
консолидированных \\
бюджетов субъектов \\
РФ в основных \\
рыночных ценах, \\
млрд. руб. \\
\end{tabular} & 2999,9 & 3797,3 & 4828,5 & 6198,8 & 5926,6 & 6537,3 & 7644,2 & 8064,5 & 8165,1 & 8905,7 & 9308,2 & 9923,8 \\
\hline \begin{tabular}{|l} 
Индексы-дефляторы \\
ВВП, в \% к 2005 году
\end{tabular} & 100,0 & 115,2 & 131,1 & 154,7 & 157,8 & 180,2 & 208,8 & 226,2 & 237,0 & 254,3 & 275,2 & 285,1 \\
\hline \begin{tabular}{|c|} 
Межбюджетные \\
поступления в \\
консолидированные \\
бюджеты субъектов \\
РФ в ценах 2005 года, \\
млрд. руб. \\
\end{tabular} & 424,5 & 505,0 & 478,5 & 732,2 & 942,7 & 776,3 & 787,4 & 718,2 & 639,1 & 656,9 & 587,5 & 553,5 \\
\hline $\begin{array}{c}\text { Доходы } \\
\text { консолидированных } \\
\text { бюджетов субъектов } \\
\text { РФ в ценах } 2005 \text { года, } \\
\text { млрд. руб. }\end{array}$ & 2999,9 & 3296,3 & 3683,1 & 4007,1 & 3756,0 & 3627,9 & 3660,2 & 3565,5 & 3444,7 & 3501,5 & 3382,4 & 3480,8 \\
\hline \begin{tabular}{|c} 
Прирост суммы \\
межбюджетных \\
поступлений в \\
консолидированные \\
бюджеты субъектов \\
РФ, в \% к \\
предыдущему году
\end{tabular} & - & 19,0 & $-5,2$ & 53,0 & 28,8 & $-17,7$ & 1,4 & $-8,8$ & $-11,0$ & 2,8 & $-10,6$ & $-5,8$ \\
\hline \begin{tabular}{|c|} 
Прирост суммы \\
доходов \\
консолидированных \\
бюджетов субъектов \\
РФ, в \% к \\
предыдущему году
\end{tabular} & - & 9,9 & 11,7 & 8,8 & $-6,3$ & $-3,4$ & 0,9 & $-2,6$ & $-3,4$ & 1,6 & $-3,4$ & 2,9 \\
\hline
\end{tabular}

* таблица рассчитана и составлена автором на основе данных: Консолидированный бюджет Российской Федерации и бюджетов государственных внебюджетных фондов [Электронный ресурс] // Федеральное казначейство: информачия официального сайта. URL: http://www.roskazna.ru/ispolnenie-byudzhetov/konsolidirovannyjbyudzhet/ (дата обращения: 20.06.2017)

Для расчета ковариации и коэффициента линейной корреляции также предварительно необходимо произвести оценку разброса значений анализируемых показателей с целью выявления аномальных значений, снижающих достоверность аппроксимации. Сделать это можно путем визуального анализа диаграммы разброса. Так, на рис. 1 представлена 
плоскость, на которой по оси абсцисс (ось X) отложены значения прироста суммы межбюджетных поступлений, а по оси ординат (ось У) отложены значения прироста суммы доходов консолидированных бюджетов субъектов РФ.

Анализ разброса точек данных позволяет выделить ряд аномалий. В частности, речь идет о значениях за $2007(-5,2 ; 11,7)$ и $2009(28,8,-6,3)$ годы. Исключим их из дальнейшего анализа. На основе оставшихся данных произведем расчет ковариации и коэффициента линейной корреляции. Упростить процедуру расчета можно при помощи табличного редактора Excel, в котором присутствуют соответствующие функции.

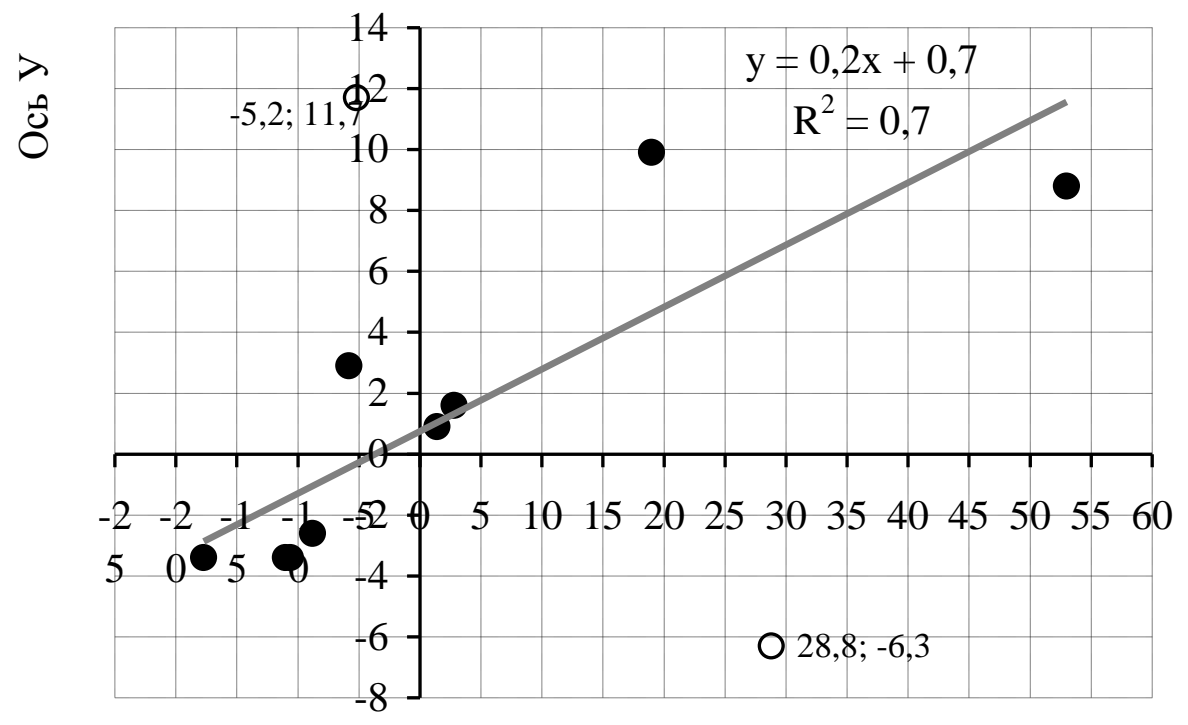

Ось X

Рисунок 1. Связь между приростом суммы межбюджетных поступлений (ось Х) и приростом суммы доходов (ось У) консолидированных бюджетов субъектов РФ, в период с 2005 по 2016 годь *

*диаграмма построена автором на основе данньх табл. 1

Поскольку табличный редактор Excel производит расчет ковариации в качестве промежуточного действия при расчете коэффициента линейной корреляции, и так как в рамках проводимого анализа конечным интересом обладает теснота связи, характеризуемая именно коэффициентом линейной корреляции, а расчет ковариации предлагалось произвести лишь в качестве промежуточного действия, то представляется возможным сразу перейти к расчету коэффициента линейной корреляции.

Воспользовавшись функцией «КОРРЕЛ» получим значение линейного коэффициента корреляции между двумя диапазонами ячеек, в которых 
содержатся значения анализируемых показателей, rху = 0,9. Данное значение свидетельствует о наличии тесной линейной связи между приростом суммы межбюджетных поступлений и приростом суммы доходов консолидированных бюджетов субъектов РФ, в период с 2005 по 2016 годы. Таким образом, если предположить, что причиной является увеличение суммы межбюджетных поступлений, то следствием будет тенденция к увеличению суммы доходов консолидированных бюджетов субъектов РФ.

Уравнение регрессии, отражающее взаимосвязь между показателями прироста суммы межбюджетных поступлений и прироста суммы доходов консолидированных бюджетов субъектов РФ в период с 2005 по 2016 годы, имеет вид $\hat{\mathrm{y}}=0,2 \mathrm{x}+0,7$, а значение коэффициента достоверности аппроксимации R2=0,7.

Данное значение R2 говорит о том, что уровень достоверности полученной функции достаточно высок - с ее помощью может быть описано 7 из 10 реально наблюдаемых точек данных. Следовательно, можно полагать, что в среднем в 7 случаев из 10 увеличение факторного признака $\mathrm{x}$ (прирост суммы межбюджетных поступлений) будет способствовать увеличению результирующего признака у (прирост суммы доходов консолидированных бюджетов субъектов РФ). Причем увеличению факторного признака на 1\% в среднем будет соответствовать увеличение результирующего признака на $0,2 \%$.

В целом же проведенное выше исследование подтверждает высокую зависимость доходов и, соответственно, расходов субфедерального уровня бюджетной системы от федеральных межбюджетных трансфертов. Данная зависимость несет в себе определенные риски для всей социальноэкономической системы страны, среди которых наиболее важным представляется риск неисполнения государством части своих обязательств в социальной сфере. Поскольку именно на субфедеральном уровне сосредоточена большая часть государственных социальных услуг, и так как межбюджетные трансферты по большей части направлены именно на выравнивание возможностей местной власти в их предоставлении, то сокращение финансирования межбюджетных трансфертов из федерального бюджета будет способствовать повышению указанного риска. Причем подобного рода сокращение уже происходит. И происходит оно на фоне усиления централизации национальной бюджетной системы, сопровождаемого 
сокращением реальных доходов и увеличением реальных расходов, а также и увеличением дефицита и долга федерального бюджета.

Данное противоречие проявилось и при рассмотрении законопроекта о правке государственного бюджета 2017 года - стандартной процедуре в Государственной Думе, которая предусмотрена для корректировок действующего финансового плана с целью его адаптации к текущим экономическим реалиям.

В этом контексте с позиций нашего исследования особый интерес представляет относительная стабильность мировых цен на нефть, которые почти на четверть оказались выше заложенного в бюджет уровня. Соответственно бюджетные доходы возрастают на 1,2 трлн. руб. и позволяют существенно уменьшить напряженность в соотношениях доходов-расходов-дефицита. При этом основная часть дополнительных доходов сформирована именно благодаря подорожавшим энергоносителям. Получается формирование новой тенденции если в последние пару лет так называемая сырьевая зависимость государственного бюджета (как впрочем и всей национальной экономики) в какой-то мере снижалась в соответствии с понижением нефтяных цен, то в текущем году картина стала обратной. Так, Счетная палата в своем заключении на законопроект указала, что доля нефтегазовых доходов в общем объеме поступлений увеличивается с 37,4\% до 39,3\%, а ненефтегазовых - понижается с $62,6 \%$ до 60,7\% [2]. В случае дальнейшего роста цен такая тенденция будет только усиливаться.

Это означает, что возможности межбюджетных трансфертов также находятся в тесной зависимости от состояния мирового углеводородного рынка. Особенно с учетом изменений в структуре статей, агрегирующих межбюджетные трансферты из федерального бюджета. Как известно, в последние годы все ранее существовавшие статьи были заменены тремя новыми - дотации на выравнивание бюджетной обеспеченности субъектов Российской Федерации и муниципальных образований, иные дотации и прочие межбюджетные трансферты общего характера. При этом, резко сократилась общая сумма межбюджетных расходов федерального бюджета (в конкретных цифрах - с 4135,9 млрд. руб. до 651,3 млрд. руб.). Формально это было объяснено разнесением различных межбюджетных расходов по другим функциональным статьям. Но по мнению ряда специалистов, по сути дела здесь стали отражаться расходы преимущественно общего характера, которые не отражают всю глубину исследуемой проблематики $[9,11]$. Преодоление данного 
положения дел за счет роста нефтяных цен, по мнению специалистов, невозможно, поскольку существует множество факторов их ограничивающих в ныне существующих пределах.

Таким образом, налицо усиление системных противоречий в сфере межбюджетных отношений, которые характеризуются большим количеством участников. Происходит это в условиях, когда объективно необходимой становится выработка новой общей концепции социально-экономического развития, о чем отмечалось ранее, общепринятых принципиальных основ которой еще нет ни в научном сообществе, ни в гражданском обществе. Грядущая цифровая экономика пока не прописана ни в одном из приемлемых системных вариантов.

В такой ситуации в сфере межбюджетных отношений необходимо создать новый финансовый инструмент, который позволил бы одновременно осуществлять межбюджетные трансферты в существующем формате и последовательно формировать новые экономические отношения. Таковой, на наш взгляд, может стать технология блокчейн.

Как известно, технология блокчейнов изначально была эффективно использована при создании криптовалют. Но постепенно она находит все больше областей своего применения - используется в базах данных DNSзаписей, тестируется Шведским земельным реестром на предмет перевода на ее основу базы данных по земельным участкам, ставится вопрос о создании корпоративного блокчейна и т.п. Существует и определённое осторожнонегативное восприятие этой технологии, например, со стороны Международной межбанковской системы передачи информации и финансовых транзакций SWIFT. По мнению руководителя Сбербанка России Г. Грефа технология блокчейн по своему содержанию сопоставима с новым интернетом [5]. Активно обсуждается проблематика создания корпоративного блокчейна.

Сам блокчейн представляет собой определенную последовательность блоков, содержащих реальные транзакции участников этой системы. Одним из наиболее важных результатов ее функционирования является возрастание функциональной роли непосредственных участников, что будет очень важным именно в сфере межбюджетных отношений в условиях, когда резко сокращается потенциал федеральных трансфертов из-за сокращения нефтегазовых доходов. При этом следует учитывать и то, что последние данные по результатам социологических исследований показывают отсутствие у населения нашей страны предубеждения против налоговых изъятий, но при определенных и 
достаточно жестких условиях - открытости бюджета и адресного использования его ресурсов [8].

Формирование и введение в повседневную практику финансового инструментария реализации межбюджетных отношений на основе технологии блокчейн должно стать одним из ведущих национальных проектов стратегического социально-экономического развития. Это позволит преодолеть накопившиеся системные противоречия в сфере межбюджетных отношений и адаптировать бюджетную систему к вызовам формирующейся цифровой экономики.

***

1. Баклаева Н.М. Повышение эффективности межбюджетного регулирования на региональном уровне / Сборник материалов международной научно-практической конференции ПФ РГТЭУ 01-03 июня 2012 г. «Правовое регулирование отдельных сфер жизнедеятельности общества: теория и практика (опыт Кавказа)». Том 2. - Пятигорск: «РИА-КМВ», 2012. - С. 7-16.

2. В бюджет долили нефти // Коммерсантъ. - 10.06.2017. - №103 (6097). - C. 1. URL: http://kommersant.ru/daily/102955.

3. Гаджикурбанов Д.М., Бердичевский И.В. «Налоговый потенциал» в системе экономических категорий // Вестник Финансового университета. - 2015. - №6. - С. 96106.

4. Галазова С.С., Булацев А.С. Межбюджетные отношения в системе региональной экономики // Экономика и предпринимательство. - 2015. - №12-1 (65-1). - С.1061-1064.

5. Греф Г. России требуется новая система управления. URL: http://www.bbc.com/russian/business/2016/05/160522_gref_skolkovo_lecture.

6. Ермаков В.В. Управленческие и правовые новации в межбюджетных отношениях // Право и управление. XXI век. - 2015. - №2 (35). - С.85-91.

7. Иванова Н.Г., Цепа М.В. Теория бюджетного федерализма и российская практика // Вестник Финансового университета. - 2014. - №4 (82). - С.54-63.

8. Налоги по собственному желанию. Когда граждане готовы отдавать государству больше. URL:http://www.kommersant.ru/doc/3338641.

9. Сафин О.И. Теоретические вопросы разработки формул расчета трансфертов в межбюджетных отношениях // Дискуссия. - 2015. - №10. - С. 64-69.

10. Татуев А.А., Шаш Н.Н. Эффективность межбюджетного регулирования // Вестник Северо-Осетинского государственного университета имени Коста Левановича Хетагурова.- 2014.- №3.- С. 377-385.

11. Хугаева М. Межбюджетные отношения в Российской Федерации: основные тенденции развития в 2000-2012 гг. // Общество и экономика. - 2014. - №11. - С.101-120.

12. Юшков А.О., Одинг Н.Ю., Савулькин Л.И. Роль субвенций в российской системе бюджетного федерализма // Вопросы экономики. - 2016. - №10. - С.49-64. 